Letter to the Editor

\title{
Has the increasing incidence of Chlamydia and Gonorrhoea resulted in increased chlamydial and gonococcal conjunctivitis presentations? Results from Melbourne, Australia, from 2000- 2017
}

\author{
Philip Rothschild MBBS, ${ }^{1}$ Ye Chen FRANZCO, ${ }^{2}$ Kristen Wells FRANZCO, ${ }^{2}$ Justin C \\ Sherwin MChir FRANZCO ${ }^{2}$ and Carmel Crock FACEM ${ }^{2}$
}

${ }^{1}$ Launceston Clinical School, The University of Tasmania. Launceston, 7250, Australia

${ }^{2}$ Royal Victorian Eye and Ear Hospital. East Melbourne, VIC, Australia

Received 25 July 2018; accepted 4 August 2018

Conflict of interest: None

Funding sources: None

This is the author manuscript accepted for publication and has undergone full peer review but has not been through the copyediting, typesetting, pagination and proofreading process, which may lead to differences between this version and the Version of Record. Please cite this article as doi: $10.1111 /$ ceo.13373

This article is protected by copyright. All rights reserved. 
The most prevalent sexually transmitted infection (STI) globally is Chlamydia trachomatis, and commonly leads to ocular infection ${ }^{2}$. Whilst less prevalent, Neisseria gonorrhoea infection can lead to ocular infection causing severe microbial keratitis and corneal perforation ${ }^{3}$. The incidence of non-ocular $C$. trachomatis infection and N. gonorrhoea infection in Victoria has markedly increased since 2000 yet it remains unknown whether the incidence of gonococcal conjunctivitis (GC) and chlamydial conjunctivitis (CC) has increased proportionally. Accordingly, we evaluated new cases of GC and CC presenting to the Royal Victorian Eye and Ear Hospital (RVEEH) in Melbourne, Australia.

We extracted serological data from RVEEH clinical records, with confirmed CC or GC cases being defined as PCR or positive culture for CC and GC, respectively. Data was extracted until Dec 2017, commencing Jan 2000 for GC, and from Jan 2006 for CC (when PCR was first used). Incidence of chlamydial and gonococcal genitourinary disease was extracted from the Australian Department of Health. ${ }^{4}$

From 2000 to 2017 there were 480,415 outpatient initial eye RVEEH ED presentations, with 4325 cases diagnosed as bacterial conjunctivitis at presentation. Twenty-four ( $0.55 \%)$ were culture positive for GC, with between 0 to 3 new cases annually. There were 221 confirmed cases of CC, with between 8 to 29 new cases annually. There were similar gender proportions of GC. Of men (52\%), mean (range) age was 42.6 (18-74) years and for women 35.1 (19-53) years. For CC cases, most (65\%) were male with mean age 29.6 (16 to 68 ) years, 
and for females mean 24.5 (13 to 56) years. The frequency of GC and CC presentations remained relatively each year, with their presentation rate increasing by an average of 0.23 or 0.03 cases / 10,000 ED presentations annually, respectively (Figure 1).

It remains unclear why the number of CC and GC presentations at RVEEH didn't increase consistent with an increasing incidence of genitourinary $C$. trachomatis and $N$. Gonorrhoea in Victoria. The small increase in absolute numbers of CC and GC seen is in keeping with increased overall RVEEH ED presentations over the study period. As ocular infection is typically caused by autoinoculation ${ }^{5}$, this raises the question of whether this disparity could be due to improved awareness of hand hygiene amongst the general population, resulting in reduced hand to eye transmission of genital disease. This discrepancy could also be due to increased screening for genital disease as well as a lower threshold for treatment, ultimately leading to fewer ocular presentations of these diseases. However, one major study limitation is that we investigated the rate of GC and CC presentations only to a solitary hospital and consequently, the Victorian incidence of GC and CC cannot be confidently evaluated.

In conclusion, an increase in genital infection in Victoria did not correspond with an increase in GC and CC presentations to the RVEEH. Although C. trachomatis and $N$. gonorrhoeae are both significant causes of conjunctivitis, the frequency of new ocular infections caused by these STIs are not increasing in this study population.

\section{REFERENCES}

1. Report on global sexually transmitted infection surveillance 2015. Geneva: World Health Organisation; 2016. 
2. Datta B, Njau F, Thalmann J, Haller H, Wagner AD. Differential infection outcome of Chlamydia trachomatis in human blood monocytes and monocytederived dendritic cells. BMC Microbiol. 2014; 14(1): 209.

3. Kanski JJ, Bowling B. Clinical ophthalmology: a systematic approach: Elsevier Health Sciences; 2011.

4. National Notifiable Diseases Surveillance System: Australian Department of Health; 2018 [Accessed from http://www.health.gov.au/nndssdata on the 1st of June 2018]

5. Stenberg K, Mardh PA. Chlamydial conjunctivitis in neonates and adults. History, clinical findings, and follow-up. Acta Ophthalmol. 1990;68(6):651-7. 


\section{University Library}

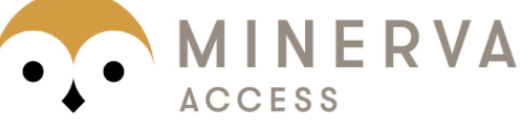

A gateway to Melbourne's research publications

Minerva Access is the Institutional Repository of The University of Melbourne

Author/s:

Rothschild, P;Chen, Y;Wells, K;Sherwin, JC;Crock, C

Title:

Has the increasing incidence of chlamydia and gonorrhoea resulted in increased chlamydial and gonococcal conjunctivitis presentations? Results from Melbourne, Australia, from 2000 to 2017

Date:

2019-03-01

Citation:

Rothschild, P., Chen, Y., Wells, K., Sherwin, J. C. \& Crock, C. (2019). Has the increasing incidence of chlamydia and gonorrhoea resulted in increased chlamydial and gonococcal conjunctivitis presentations? Results from Melbourne, Australia, from 2000 to 2017.

CLINICAL AND EXPERIMENTAL OPHTHALMOLOGY, 47 (2), pp.289-291. https:// doi.org/10.1111/ceo.13373.

Persistent Link:

http://hdl.handle.net/11343/285205 